\title{
Effect of L-thyroxine on gastric secretion in the pylorus-ligated rat
}

\author{
D. W. BLAiR, M. J. WILLIAMS, A. J. CARR, AND S. J. KILPATRICK ${ }^{1}$ \\ From the Departments of Surgery, Materia Medica and Therapeutics, \\ Pathology, and Statistics, University of Aberdeen
}

EDITORIAL SYNOPSIS L-thyroxine is shown to have an inhibitory effect on gastric secretion initially, but gastric secretion returns to normal some weeks later in spite of continued administration of L-thyroxine.

The hormones secreted by the major endocrine glands are now known to exert an important influence on gastric secretion in both man and animals. Scant attention, however, has been given to the possible effect of the thyroid hormones in this respect, although it has recently been shown that the mean acid output following maximal histamine stimulation is much lower in patients with confirmed hyperthyroidism than in normal subjects (Williams and Blair, 1964).

The first observations on the effect of thyroid hormone on gastric secretion were those of Hardt (1916) who fed $10 \mathrm{~g}$. of desiccated thyroid daily to two Pavlov-pouch dogs and found a reduction in the acidity and rate of secretion of gastric juice. Subsequent workers confirmed these observations (Thomsen, 1925; Truesdell, 1926; Chang and Sloan, 1927) and whole thyroid was also found to diminish secretion of gastric juice in rabbits (Green and Kunde, 1930) and in rats (Goldsmith and Nasset, 1959).

More detailed studies of the effects of thyroid hormones on gastric secretion were performed by Nasset, Logan, Kelley, and Thomas (1959) and their observations suggested that the inhibitory effect of whole thyroid might be mediated through the vagus. This inhibitory effect appeared to be quite independent of the calorigenic action of thyroid hormone, as the changes in acid secretion did not correlate with alterations in the B.M.R. and merely raising the B.M.R. by the administration of dinitrophenol was without effect on gastric secretion (Nasset and Goldsmith, 1961). They also found that the crystalline thyroid hormones, including L-thyroxine, produced less striking depression of acid secretion, an observation they confirmed by studies on rats

'Present address: Department of Biometry, Medical College of Virginia, Richmond, Virginia, U.S.A.
(Goldsmith and Nasset, 1959), and they suggested that the thyroid gland might produce a nonthyroxine factor which influenced the stomach.

Hypertrophy of the adrenal glands has also been noted to follow thyroid feeding in rats (Goldsmith and Nasset, 1959; Sessions, Rand, Hiestand, Hardy, and Fand, 1961), and as the concentration of circulating adrenal hormones is known to influence gastric acid secretion (Kyle and Welbourn, 1956), the possibility of these glands being implicated in the inhibitory effect of thyroid hormone on the stomach was considered.

Although most of the previous reports indicate that the administration of whole thyroid inhibits gastric secretion, erratic results have been obtained from the use of crystalline thyroid compounds such as L-thyroxine. The exact mechanism involved in any possible inhibitory effect on gastric secretion also remains uncertain.

The following studies were therefore planned to investigate the effect of L-thyroxine on the secretory activity of the stomach in the pylorus-ligated rat.

\section{METHODS}

White rats of the Sprague-Dawley strain weighing $200 \mathrm{~g}$. or over at the start of each experiment were used. The animals were kept in identical wire cages, in a thermostatically controlled room, care being taken to avoid undue stress from overcrowding. Before each study was commenced, time was allowed for the rats to accustom themselves to their surroundings. Food and water were made easily available and plentiful, a standard laboratory diet being used.

For 24 hours before each experiment, the animals were starved in individual wide-mesh metabolic cages, only water being allowed during this period. This was discontinued at the start of the test, at which time the animals were weighed. This weight was used in all subsequent calculations. 
Gastric juice was collected by a modification of the pylorus ligation technique described by Shay and his colleagues (Shay, Komarov, Fels, Meranze, Gruenstein, and Siplet, 1945; Shay, Sun, and Gruenstein, 1954). This is a valid method for collecting gastric secretion in the rat because of its inability to vomit. The stomach, in the fasting rat, also secretes at a constant rate, close to maximal secretion, and so observations can be made over a fixed period of time. The optimum period of collection for this type of experiment is four hours (Shay et al., 1954) and was used throughout.

Under light ether anaesthesia the abdomen was opened through a midline epigastric incision, and the pylorus exposed without handling the stomach. A fine thread was then tied round the pylorus, care being taken to avoid inclusion of adjacent blood vessels. The wound was then closed and the animal returned to its cage where it quickly regained consciousness. The stomach was not washed out at the time of pylorus ligation as advocated by Shay et al. (1954) as this has been shown to be an unnecessary procedure (Kyle, 1956).

Four hours later, the animal was again anaesthetized, the abdomen opened, and the stomach removed after clamping the pylorus and the lower end of the oesophagus, following which the animal was killed without regaining consciousness. By opening the stomach along its greater curvature the contents could be collected in a graduated centrifuge tube, the stomach then being pinned on cork and fixed in formol saline for histological examination. The presence of blood in the gastric juice, or debris in excess of $0.6 \mathrm{ml}$. following centrifugation, was an indication to discard the specimen.

The volume of gastric juice was measured in millilitres and the concentration of free acid determined by titration with one fiftieth normal sodium hydroxide, using Topfer's reagent as indicator. Free acid output was then calculated as milliequivalents $\mathrm{HCl}$ per $100 \mathrm{~g}$. body weight.

In one of the experiments, the pituitary and adrenal glands were removed immediately after death, dried on filter paper and weighed before evaporation could take place.

The pituitary gland was exposed by opening the skull and elevating the frontal lobes. Removal of the thin film of meningeal tissue covering the gland allowed it to be dislodged from its position.

The adrenal glands were approached by extending the abdominal wound laterally below the rib margins on both sides, and on raising the liver, the glands could be picked up and excised. The surrounding fat was carefully dissected off the gland before weighing. The weights of the pituitary and adrenal glands were calculated as milligrammes per $100 \mathrm{~g}$. body weight.

Three studies were carried out to observe the effect on acid secretion of administering different quantities of $\mathrm{L}$-thyroxine for variable lengths of time. As far as possible equal numbers of control and test animals were used in each study. Sodium L-thyroxine dissolved in $2.5 \%$ propylene glycol was administered subcutaneously to test animals, and equivalent amounts of propylene glycol alone were administered to control animals.

Because of wide variations in acid secretion in individ- ual rats, large numbers of animals have to be used to achieve definitive results (Shay et al., 1954) and simultaneous control animals must be studied. Pilot studies were therefore initially performed on small numbers of animals in an attempt to show when changes in gastric secretion were most likely to occur. Confirmatory experiments were then performed using large numbers of animals, the sacrifices being carried out at times which coincided with critical stages in the pilot study.

\section{STUDY 1: THE EFFECT OF REPEATED SMALL DOSES OF L-THYROXINE ON GASTRIC SECRETION}

PILOT STUDY The 52 rats used in this experiment were divided into two groups of equal number and sex distribution, forming a control and test group. The test animals received $40 \mu \mathrm{g}$. L-thyroxine on alternate days, until the allotted day of sacrifice for each was attained. As tests were carried out at weekly intervals, observations were made on rats receiving L-thyroxine for periods ranging from one to nine weeks.

\section{TABLE I}

THE EFFECT OF $40 \mu \mathrm{G}$. L-THYROXINE ON ALTERNATE DAYS FOR ONE to NINE WEEKS ${ }^{1}$

\begin{tabular}{llll} 
Week & Test & Control & Test-control \\
\cline { 3 - 3 } & & & Difference \pm S.E. \\
\hline 1 & 0.255 & 0.361 & $-0.106 \pm 0.10$ \\
2 & 0.124 & 0.200 & $-0.076 \pm 0.14$ \\
3 & 0.158 & 0.418 & $-0.260 \pm 0.12$ \\
4 & 0.100 & $0.186^{2}$ & $-0.086 \pm 0.12$ \\
5 & 0.111 & 0.196 & $-0.085 \pm 0.09$ \\
6 & 0.114 & 0.247 & $-0.133 \pm 0.09$ \\
7 & 0.172 & 0.202 & $-0.030 \pm 0.08$ \\
8 & 0.207 & $0.144^{2}$ & $+0.063 \pm 0.04$ \\
9 & 0.296 & 0.199 & $+0.097 \pm 0.09$
\end{tabular}

${ }^{1}$ Mean acid outputs (mEq. free $\mathrm{HCl}$ per $100 \mathrm{~g}$. body weight) control and test means are based on three animals per week.

${ }^{2}$ The mean of two animals.

The mean acid outputs over the nine-week period are shown in Table I. When assessed over the whole period, these results do not show a significant inhibition of acid output $(0.10>P>0.05)$ but the pattern of secretion suggests the presence of an inhibitory effect during the first seven weeks which is lost in the remaining two weeks.

No macroscopic lesions of the gastric mucosa were observed, and histological examination of longitudinal sections of full stomach thickness, taken parallel and adjacent to the greater curvature, revealed no cellular abnormality in either test or control animals. The ratio of the mucosal thickness to muscle thickness of each stomach in the test group was compared subjectively with similar ratios in the control animals. No obvious difference was noted whether or not secretion of acid had been inhibited. 
TABLE II

MEAN PITUITARY WEIGHTS (MG. PER 100 G. BODY WEIGHT) OF RATS SACRIFICED IN STUDY

\begin{tabular}{|c|c|c|c|c|c|}
\hline \multirow[t]{2}{*}{ Sex } & \multicolumn{2}{|l|}{ Test } & \multicolumn{2}{|c|}{ Control } & \multirow{2}{*}{$\frac{\text { Test-control }}{\text { Difference } \pm \text { S.E. }}$} \\
\hline & No. & $M e a n \pm S . D$. & No. & Mean $\pm S . D$ & \\
\hline $\begin{array}{l}\text { Males } \\
\text { Females }\end{array}$ & $\begin{array}{l}13 \\
12\end{array}$ & $\begin{array}{l}2 \cdot 67 \pm 0.36 \\
4 \cdot 32 \pm 0.73\end{array}$ & $\begin{array}{l}12 \\
12\end{array}$ & $\begin{array}{l}2.58 \pm 0.54 \\
4.48 \pm 0.81\end{array}$ & $\begin{array}{l}+0.09 \pm 0.18 \\
-0.16 \pm 0.32\end{array}$ \\
\hline
\end{tabular}

The weights of the pituitary glands, corrected for body weight, are shown in Table II. Since the mean difference between test and control is less than the standard error in each sex, these differences were clearly not significant. The mean pituitary weights per $100 \mathrm{~g}$. are tabulated separately for each sex. The mean female pituitary gland weights (uncorrected for body weight) are not significantly greater than the means for males so that the apparent sex differences in Table III are largely due to sex differences in mean body weight.

The mean adrenal gland weights, corrected for body weight, are shown in Table III. There is some indication of an increase in mean adrenal weight in the test animals, the test means being greater than the control means in each week except the third. An analysis of variance, however, showed no significant difference among the overall means for different weeks and the difference between adrenal weights in the 27 test animals and the 27 control animals for

\section{TABLE III}

MEAN ADRENAL WEIGHTS (MG. PER 100 G. BODY WEIGHT) OF RATS SACRIFICED IN STUDY 1

\begin{tabular}{|c|c|c|c|c|c|}
\hline \multirow[t]{2}{*}{ Week } & \multicolumn{2}{|c|}{$\begin{array}{l}\text { No. and Sex of } \\
\text { Each Group }\end{array}$} & \multirow[t]{2}{*}{ Test } & \multirow[t]{2}{*}{ Control } & \multirow{2}{*}{$\frac{\text { Test-control }}{\text { Difference } \pm S . E .}$} \\
\hline & Male & Female & & & \\
\hline $\begin{array}{l}1 \\
2 \\
3 \\
4 \\
5 \\
6 \\
7 \\
8 \\
9\end{array}$ & $\begin{array}{l}1 \\
2 \\
1 \\
2 \\
1 \\
2 \\
1 \\
2 \\
0\end{array}$ & $\begin{array}{l}2 \\
1 \\
2 \\
1 \\
2 \\
1 \\
2 \\
1 \\
3\end{array}$ & $\begin{array}{l}17.94 \\
21.61 \\
24.90 \\
19.56 \\
26.58 \\
20.61 \\
28.89 \\
21.99 \\
32.68\end{array}$ & $\begin{array}{l}17 \cdot 09 \\
19 \cdot 57 \\
25 \cdot 79 \\
17 \cdot 56 \\
18 \cdot 60 \\
16 \cdot 20 \\
23 \cdot 44 \\
16 \cdot 42 \\
26 \cdot 46\end{array}$ & $\begin{array}{l}+0.85 \pm 3.99 \\
+2.04 \pm 6.65 \\
-0.89 \pm 8.37 \\
+2.00 \pm 6.70 \\
+7.98 \pm 4.10 \\
+4.41 \pm 7.84 \\
+5.45 \pm 7.84 \\
+5.57 \pm 7.58 \\
+6.22 \pm 4.04\end{array}$ \\
\hline Combined & 12 & 15 & $23 \cdot 86$ & $20 \cdot 13$ & $+3.73 \pm 2.01$ \\
\hline
\end{tabular}

the whole period of study just failed to reach significance $(0.1>\mathrm{P}>0.05)$.

We concluded, however, that this suggested a small, but real increase in the adrenal weights of test animals which a larger experiment would have detected.

CONFIRMATORY STUDY To confirm the impression that acid secretion was inhibited during the first seven weeks of L-thyroxine administration and was subsequently lost, two further experiments were performed on a large group of animals. Fifty-eight male rats were used and randomly allocated to test or control groups. the test animals again receiving $40 \mu \mathrm{g}$. L-thyroxine on alternate days. In the first experiment, animals were sacrificed after exactly 14 days, this being selected to coincide with a period when an inhibition of acid secretion was expected. In the second experiment, sacrifices were carried out after eight weeks at which time no inhibition was anticipated.

The mean acid outputs in these experiments are given in Table IV. At two weeks, the mean acid output in the test animals was half that of the controls, this difference being highly significant $(P<0.001)$. At eight weeks, however, no significant difference existed between the control and test animals.

This confirms the previous impression that the repeated administration of L-thyroxine $(40 \mu \mathrm{g}$. on alternate days) inhibits gastric secretion in the pylorus-ligated rat although this inhibitory effect is lost after about seven weeks even although the stimulus is maintained.

Suspecting that this loss of inhibitory effect might have been due to an inadequate dose of L-thyroxine

\section{TABLE IV}

MEAN ACID OUTPUT (MEQ. FREE HCl PER 100 G. BODY WEIGHT)

IN RATS RECEIVING $40 \mu \mathrm{g}$. L-THYROXINE ON ALTERNATE DAYS FOR TWO WEEKS AND EIGHT WEEKS

\begin{tabular}{|c|c|c|c|c|c|}
\hline \multirow[t]{2}{*}{ Duration } & \multicolumn{2}{|l|}{ Test } & \multicolumn{2}{|c|}{ Control } & Test-control \\
\hline & No. & Mean $\pm S . D$. & No. & Mean \pm S.D. & Difference \pm S.E. \\
\hline $\begin{array}{l}\text { Two weeks } \\
\text { Eight weeks }\end{array}$ & $\begin{array}{l}15 \\
14\end{array}$ & $\begin{array}{l}0.199 \pm 0.139 \\
0.397 \pm 0.178\end{array}$ & $\begin{array}{l}18 \\
11\end{array}$ & $\begin{array}{ll}0.405 & \pm 0.139 \\
0.305 & \pm 0.156\end{array}$ & $\begin{array}{l}-0.206 \pm 0.049 \\
+0.092 \pm 0.068\end{array}$ \\
\hline
\end{tabular}




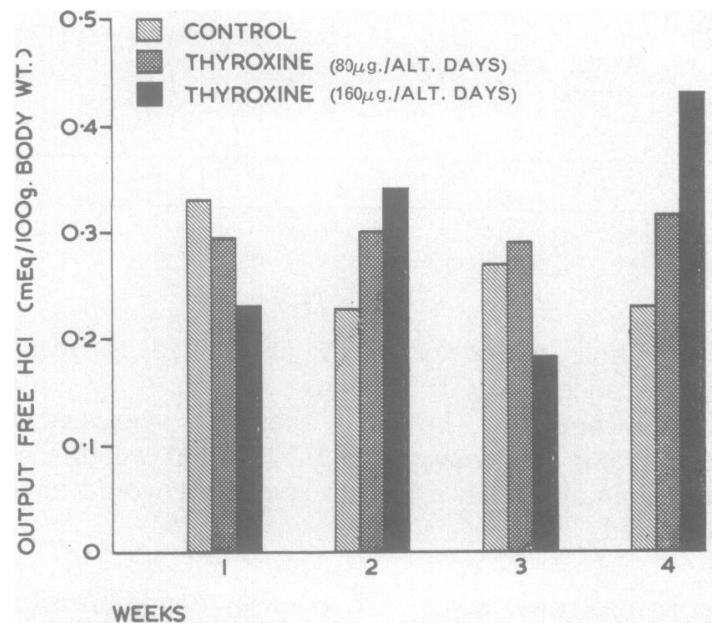

FIG. 1 The effect of different doses of L-thyroxine on acid output in pylorus-ligated rats. Each column represents the mean of three animals.

allowing the animals in some way to escape from its influence, a further study was planned to observe the effects of repeated administration of larger doses.

STUDY 2: THE EFFECT OF REPEATED LARGE DOSES OF L-THYROXINE ON GASTRIC SECRETION (SACRIFICE WEEKLY)

PILOT STUDY In this experiment, one control and two test groups were studied simultaneously, a total of 36 male rats being used. In one test group, the animals were given $80 \mu \mathrm{g}$. L-thyroxine on alternate days, the other group receiving $160 \mu \mathrm{g}$. Lthyroxine on alternate days. Groups of animals were sacrificed at intervals ranging from one to four weeks, the experiment being terminated at this point because the thyroxine-treated animals became less able to withstand the anaesthetic and operative procedure.

The results are shown in Figure 1. Apart from a possible slight inhibitory effect at the end of the first week, the mean acid outputs in the test animals were not lowered in comparison with the controls.

Because of this possible inhibitory effect in the first week, a further experiment was planned to observe more closely any changes in gastric secretion during this period.

STUDY 3: THE EFFECT OF REPEATED LARGE DOSES OF L-THYROXINE ON GASTRIC SECRETION (SACRIFICE ON ALTERNATE DAYS)

PILOT STUDY One control and one test group of animals were studied, the test animals receiving $160 \mu \mathrm{g}$. L-thyroxine on alternate days, but sacrifices were performed on every second day instead of weekly. The experiment was continued for a period of 15 days, 48 animals being studied.

The results, which are shown in Fig. 2, suggested that acid secretion in the test animals was inhibited during the first few days of thyroxine administration but that this inhibitory effect was lost at the end of a week. These observations were made, however, using only a small number of animals and so a confirmatory study was next performed.

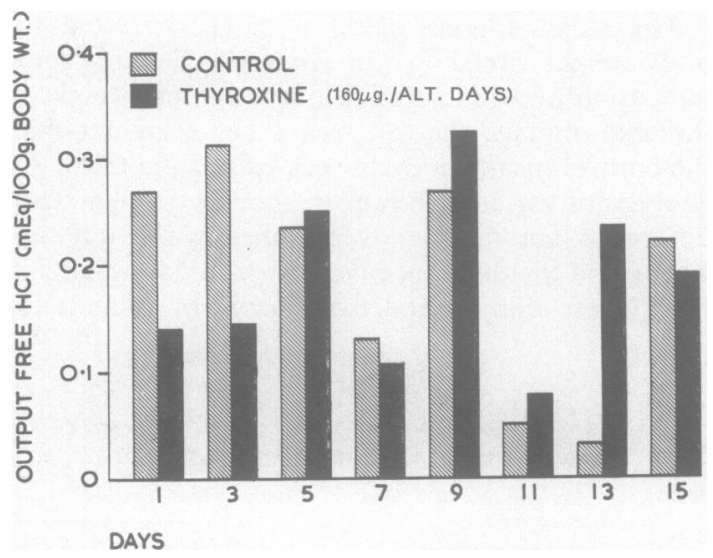

FIG. 2. The effect of $160 \mu g$. L-thyroxine on alternate days for periods ranging from one to 15 days on acid secretion in the pylorus-ligated rat. Each column represents the mean of three animals.

CONFIRMATORY STUDY Seventy-five animals were allocated randomly to either a control or test group. The test animals received $160 \mu \mathrm{g}$. L-thyroxine on alternate days, experiments being performed after either four or 14 days, the appropriate control group being sacrificed simultaneously.

TABLE V

MEAN ACID OUTPUT (MEQ. FREE HCl PER 100 G. BODY WEIGHT) IN RATS RECEIVING $160 \mu \mathrm{G}$. L-THYROXINE ON ALTERNATE DAYS FOR FOUR DAYS AND ELEVEN DAYS

\begin{tabular}{|c|c|c|c|c|c|}
\hline \multirow[t]{2}{*}{ Duration } & \multicolumn{2}{|l|}{ Test } & \multicolumn{2}{|c|}{ Control } & \multirow{2}{*}{$\frac{\text { Test-control }}{\text { Difference } \pm \text { S.E. }}$} \\
\hline & No. & Mean \pm S.D. & No. & Mean $\pm S . D$. & \\
\hline $\begin{array}{l}\text { Four days } \\
\text { Eleven days }\end{array}$ & $\begin{array}{l}20 \\
18\end{array}$ & $\begin{array}{l}0.167 \pm 0.099 \\
0.208 \pm 0.099\end{array}$ & $\begin{array}{l}19 \\
18\end{array}$ & $\begin{array}{l}0.296 \pm 0.136 \\
0.199 \pm 0.120\end{array}$ & $\begin{array}{l}-0.129 \pm 0.038 \\
+0.009 \pm 0.037\end{array}$ \\
\hline
\end{tabular}


From the mean acid outputs shown in Table $\mathrm{V}$ it can be seen that a significant inhibition of acid secretion was found in the test animals after four days $(0.01>P>0.001)$ but that this effect was lost at 14 days.

\section{DISCUSSION}

It would appear from the literature that the administration of desiccated thyroid to animals consistently reduces acid secretion from the stomach, but the crystalline thyroid compounds, such as L-thyroxine, have been erratic in their effects. In the present experiments, however, $40 \mu \mathrm{g}$. L-thyroxine administered on alternate days to pylorus-ligated rats had a definite inhibitory effect on acid secretion. This inhibitory effect was not maintained, however, the output of acid returning to normal after approximately seven weeks, despite continued thyroxine administration. Larger doses (160 $\mu \mathrm{g}$. alternate days) also showed an inhibitory effect, but paradoxically, this was even more transient, acid secretion returning to normal levels after only a few days. This variation in response with the dose level and time may explain some of the discrepancies in the previous literature.

The normal rate of thyroid hormone production in the rat, expressed as L-thyroxine, has been estimated at between 2.0 and $2.5 \mu \mathrm{g} . / 100 \mathrm{~g}$. body weight/day (Reineke and Singh, 1955; Plamondon, Selenkow, Wiswell, and Asper, 1958), giving a daily thyroid hormone production of about 4.0 to $7.5 \mu \mathrm{g}$. L-thyroxine for rats weighing 200-300 g. such as were used in the present experiments. The initial dose of L-thyroxine used was $40 \mu \mathrm{g}$. subcutaneously on alternate days, being chosen as a dose likely to produce significant metabolic effects. It is of interest, therefore, that Derblom, Johansson, and Nylander (1963) have recently noted that L-thyroxine given subcutaneously in a daily dose of $5 \mu \mathrm{g} . / 100 \mathrm{~g}$. body weight, which is about half the smallest dose used in the present study, produced no significant changes in gastric secretion or acidity in pylorus-ligated rats over a period of 30 days.

It was previously noted in experiments using desiccated thyroid that the depression of acid secretion was unaccompanied by any histological changes in the gastric mucosa (Thomsen, 1925; Sessions et al., 1961) and this was confirmed in this study. The pattern of secretory response was also more suggestive of a functional effect, the stomach being affected either directly or indirectly.

With regard to the latter, acid secretion in the pylorus-ligated rat is largely maintained by the influence of the vagal pathways and the adrenal glands (Jones and Harkins, 1958) and the effect of L-thyroxine on gastric secretion might be mediated through these influences.
Depression of vagal activity was thought to be involved in the inhibition of acid secretion which followed thyroid feeding in dogs (Nasset et al., 1959) but the pattern of response found in the present experiments with different doses of L-thyroxine make this unlikely.

Enlargement of the adrenal glands has been noted after thyroid feeding in rats (Goldsmith and Nasset, 1959; Sessions et al., 1961) and was also found with L-thyroxine in our first experiment. Because of the small number of animals studied, the results did not achieve significance but we have subsequently confirmed this response in a larger study. The adrenal enlargement was noted by Sessions and his colleagues (Sessions et al., 1961) to involve both the cortex and the medulla, and they thought that increased epinephrine (adrenaline) production might have accounted for the reduced gastric secretion found in their experiments. There is no evidence, however, that this hormone can directly influence gastric secretion and adrenal medullectomy is certainly without effect on gastric secretion in rats (Tuerkischer and Wertheimer, 1945). The concentration of circulating adrenal cortical hormones, on the other hand, is known to have a marked influence on gastric secretion. Thus, marked inhibition of acid secretion follows adrenalectomy in rats (Tuerkischer and Wertheimer, 1945; Madden and Ramsberg, 1951; Kyle and Welbourn, 1956; Jones and Harkins, 1958), while secretion is increased by cortisone administration (Kyle and Welbourn, 1956).

Although one tends to relate increase in adrenal cortical size with hypertrophy and increased activity, the enlargement may be due rather to an increase in lipid content which has been associated with relative inactivity of glandular function (Dosne and Dalton, 1941). Lipid accumulation has been noted in experimental hyperthyroidism in rats (Deane and Greep, 1947) and we have confirmed this in preliminary studies. If these observations, suggesting a paradoxical association of reduced adrenal function despire glandular enlargement, are confirmed, the adrenal cortex could play a major role in lowering acid secretion in the thyroxinetreated animals.

It is apparent, however, that more work is required to investigate the mechanisms involved in changes in acid secretion which follow the administration of L-thyroxine and also to ascertain the reason why the inhibitory effect is not maintained.

We wish to thank Professor G. Smith and Professor A. G. Macgregor for the interest they have shown in this work. We also thank Miss Edna Simpson for technical assistance, and Mrs. M. Bathgate for supervising the care of the animals. 


\section{REFERENCES}

Chang, H. C., and Sloan, J. H. (1927). Influence of experimental hypothyroidism upon gastric secretion. Amer. J. Physiol., 80, 732-734.

Deane, H. W., and Greep, R. O. (1947). A cytochemical study of the adrenal cortex in hypo- and hyperthyroidism. Endocrinology, 41, 243-257.

Derblom, H., Johansson, H., and Nylander, G. (1963). Thyroid hormone activity and gastrointestinal function. An experimental study in the rat. Acta chir. scand., suppl. 307.

Dosne, C., and Dalton, A. J. (1941). Changes in the lipoid content of the adrenal gland of the rat under conditions of activity and rest. Anat. rec., 80, 211-217.

Goldsmith, D. P. J., and Nasset, E. S. (1959). Relation of thyroid to gastric acid secretion in the anaesthetized rat. Amer. J. Physiol., 197, 1-4.

Green, M. F., and Kunde, M. M. (1930). Acidity of gastric contents of normal, cretin and hyperthyroid rabbits. Ibid., 95, 626-629.

Hardt, L. L. J. (1916). Contributions to the physiology of the stomach. XXXIII. The secretion of gastric juice in cases of gastric and duodenal ulcers. Ibid., 40, 314-331.

Jones, T. W., and Harkins, H. N. (1958). Evaluation of mechanisms involved in gastric acid secretion of pylorus-ligated rats. Gastroenterology, 35, 309-311.

Kyle, J. (1956). The Influence of the Pituitary and Adrenal Glands on Gastric Secretion. M.Ch. Thesis, Queen's University of Belfast.

and Welbourn, R. B. (1956). The influence of the adenohypophysis and the adrenal cortex on gastric secretion in the rat. Brit. J. Surg., 44, 241-247.
Madden, R. J., and Ramsberg, H. H. (1951). Adrenalectomy in the Shay rat. Gastroenterology, 18, 128-134.

Nasset, E. S., Logan, V. W., Kelley, M. L., and Thomas, M. (1959). Inhibition of gastric secretion by thyroid preparations. Amer. J. Physiol., 196, 1262-1265.

- and Goldsmith, D. P. J. (1961). Effect of thyroid on gastric secretion and metabolism. Ibid., 201, 567-570.

Plamondon, C. A., Selenkow, H. A., Wiswell, J. G., and Asper, S. P. Jr. (1958). Studies of thyroxine and some of its analogues. II. The antigoitrogenic properties of thyroxine and triiodothyronine. Bull. Johns Hopk. Hosp., 102, 88-93.

Reineke, E. P., and Singh, O. N. (1955). Estimation of thyroid hormone secretion rate of intact rat. Proc. Soc. exp. Biol. (N.Y.) 88, 203-207.

Sessions, J. T. Jr., Rand, T. S., Hiestand, F. G., Hardy, I. M., and Fand, S. B. (1961). Gastric secretory studies in thyrotoxic rats. Clin. Res., 9, 155.

Shay, H., Komarov, S. A., Fels, S. S., Meranze, D., Gruenstein, M., and Siplet, H. (1945). A simple method for uniform production of gastric ulceration in the rat. Gastroenterology, 5, 43-61.

-, Sun, D. C. H., and Gruenstein, M. (1954). A quantitative method for measuring spontaneous gastric secretion in the rat. Ibid., 26, 906-913.

Thomsen, E. (1925). Études sur l'achylie neurogène et cellulaire. Acta med. scand., 61, 522-569.

Truesdell, C. (1926). The effect of feeding thyroid extract on gastric secretion. Amer. J. Physiol., 76, 20-27.

Tuerkischer, E., and Wertheimer, E. (1945). Adrenalectomy and gastric secretion. $J$. Endocr., 4, 143-151.

Williams, M. J., and Blair, D. W. (1964). Gastric secretion in hyperthyroidism. Brit. med. J., 1, 940-944. 